\title{
Nutritional status of pregnant women reporting at Rural Health Training Centre
}

\author{
Prajakta Ganesh Joshi $^{1 *}$, Ganesh Arun Joshi², Sapna Jain', Vijaya Dubey ${ }^{3}$
}

\begin{abstract}
${ }^{1}$ Department of Obstetrics and Gynecology, L N Medical College and J K Hospital, Bhopal, Madhya Pradesh, India ${ }^{2}$ Department of Physical Medicine and Rehabilitation, CRC, Bhopal, Madhya Pradesh, India

${ }^{3}$ Rural Health Training Centre, Department of Community Medicine, L N Medical College and J K Hospital, Bhopal, Madhya Pradesh, India
\end{abstract}

Received: 29 July 2017

Accepted: 04 August 2017

\section{*Correspondence:}

Dr. Prajakta Ganesh Joshi,

E-mail: pjosh92@gmail.com

Copyright: (C) the author(s), publisher and licensee Medip Academy. This is an open-access article distributed under the terms of the Creative Commons Attribution Non-Commercial License, which permits unrestricted non-commercial use, distribution, and reproduction in any medium, provided the original work is properly cited.

\begin{abstract}
Background: United Nations had passed MDGs followed by SDGs, half of which are based on women's health. Despite best efforts, malnutrition remains a major problem that affects our country. This is a significant risk factor for maternal and foetal mortality. This study was conducted to identify current status of maternal wellbeing in villages under an RHTC to get baseline for further interventional studies in the villages.

Methods: A descriptive study was done on the rural pregnant patients attending RHTC of LNMC and JKH situated at outskirts of Bhopal was done. All pregnant women attending RHTC from January 2016 to June 2017 were studied for nutrition indicators. Their weight and height were recorded and haemoglobin was measured by Sahli's Haemoglobinometer and the data was compared. WMA Declaration of Helsinki was followed during this study.

Results: Two hundred participants in this study were between age ranges 17 to 35 years with gravidity level of the participants ranging 1 to 5. Their Body Mass Index (BMI) ranging 14 to 30. One fourth participants were having BMI of 18.5 or less and four fifth had anaemia.

Conclusions: Majority of pregnant women reporting for prenatal checkup at RHTC are malnourished and anaemic. It is recommended to study government scheme at micro level if it is serving as cash incentive for frequent and multiple pregnancy to potentially catapult the desired effect to worsen the situation of maternal health on one side and population control on the other. Health education for the rural public is recommended.
\end{abstract}

Keywords: Maternal health, Malnutrition, Prenatal care

\section{INTRODUCTION}

United Nations had passed 8 Millennium Development Goals (MDGs) to be achieved by 2015. Four out of them viz. 1 (eradicate extreme poverty and hunger), 3 (promote gender equality and empower women), 4 (reduce child mortality) and 5 (improve maternal health) can be dealt with by improving nutritional status of women in reproductive age. After conclusion of the MDGs, 17
Sustainable Developmental Goals (SDGs) are proposed now for next 15 years up to 2030. Almost half of the SDGs are based on women's health.

Despite best efforts, malnutrition remains a major problem that affects our country. The global hunger index of India is stated as severe and $15.2 \%$ of Indians are malnourished. The women are badly affected and the rural and tribal are the worst affected lot. Maternal 
malnutrition perpetuates with poverty and transmits to next generation forming a vicious cycle. UNICEF report of 2017 says that two fifths of tribal women in select states of India are malnourished. This is a significant risk factor for maternal and foetal mortality. The tribal population is affected more. ${ }^{1}$ Maternal Mortality rate was 269 in Madhya Pradesh as against 212 National figures one decade back. Justine Greening, UK Secretary of State for international development has stated that One area the report importantly highlights is the lack of data about nutrition of women and adolescent girls. $51 \%$ of women and $87 \%$ of pregnant women are anaemic in India.

Newly established Medical Colleges in Madhya Pradesh add to the healthcare facilities available for local residents at affordable cost. The rural health training centre (RHTC) of medical college caters to the need of village population free of cost. This study was conducted to identify current status of maternal wellbeing in villages under this RHTC to get baseline for further interventional studies in the villages.

\section{METHODS}

A descriptive survey of maternal health indicators was planned to be undertaken by the Department of Obstetrics and Gynaecology of LN Medical College and JK Hospital, Bhopal. It was decided to study the rural pregnant patients attending RHTC of the College situated at the outskirts of Bhopal, about $22 \mathrm{~km}$ from the college. Bhopal is the capital of Madhya Pradesh with a population of 23.68 lac out of which, only $20 \%$ is rural according to Census 2011. The sex ratio is 911 .

According to District Health Survey in 2007-08, 21\% rural mothers have access to prenatal care facilities in the district. All pregnant women attending RHTC from January 2016 through June 2017 were studied for nutrition indicators. Their weight and height were recorded and haemoglobin was measured by Sahli's Haemoglobinometer. The women were given routine antenatal advice and necessary medical care for prevention and treatment of various medical conditions. The body mass index was calculated. The normal range of body mass index and haemoglobin level during pregnancy were assessed and the data was compared. WMA Declaration of Helsinki was followed during this study.

\section{RESULTS}

The study duration was spread over a period of $1 \frac{1}{2}$ year. Two hundred pregnant women from the nearby rural population of the RHTC, LNMC and JK Hospital participated in the study. The women were between age ranges 17 to 35 years with average age of 24 years. The gravidity level of the participants ranged 1 to 5 with majority being up to $3^{\text {rd }}$ gravida. Only 10 participants gave history of past abortion.
The height of participants ranged 140 to $160 \mathrm{~cm}$ with average height of $153.6 \mathrm{~cm}$. The weight of participating women was between 30 to $76 \mathrm{~kg}$ with an average of 48 $\mathrm{kg}$. Their Body Mass Index (BMI) was calculated that ranged 14 to 30 with an average BMI of 20.4. Fifty-one participants were abnormally thin with a BMI of 18.5 or less. The BMI of all participants is depicted in figure 1 that shows $5 \%$ of participants having emaciated stature with BMI of less than 16. There were 14 overweight participants (7\%) with BMI above 25. Normal BMI levels were seen in only 92 participants (46\%).

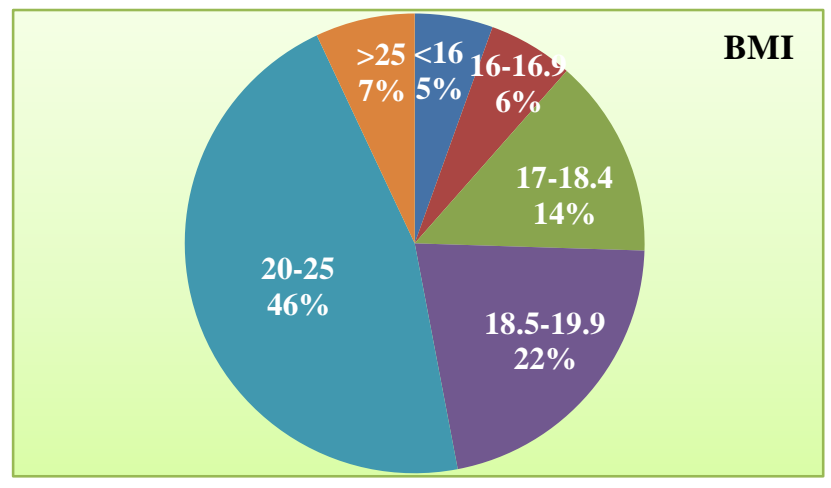

Figure 1: BMI grades of participants.

Forty-two participants $(21 \%)$ had normal haemoglobin levels of $11 \mathrm{~g} / \mathrm{dL}$ and above while an equal number $(21 \%)$ had mild anaemia with haemoglobin level between 10-11 $\mathrm{g} / \mathrm{dL}$. One hundred fourteen $(57 \%)$ had moderate anaemia with haemoglobin between the range of 7 to $10 \mathrm{~g} / \mathrm{dL}$. Two participants $(1 \%)$ had severe anaemia with haemoglobin level below $7 \mathrm{~g} / \mathrm{dL}$. Figure 2 depicts that four fifths of the participants were anaemic.

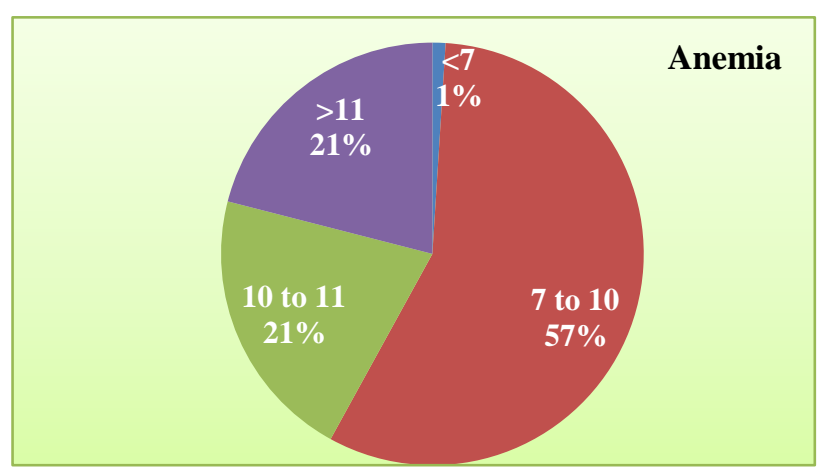

Figure 2: Haemoglobin levels of participants.

\section{DISCUSSION}

This descriptive study attempts to review the situation of maternal nutrition and health in rural population reporting to RHTC during the period of $1 \frac{1}{2}$ year from January 2016 to June 2017. The results indicate that majority of pregnant women reporting for antenatal check-up are malnourished. The women are very thin but their height is usually normal. Less than half of the participants were having normal BMI values. 
Mavalankar et al stated that maternal low weight is a much more important contributor to poor outcome than low height ${ }^{2}$. Our study found pregnant women in very low range of weight with average height.

Weight gain in pregnancy is similar across the eight populations studied by Ismail et al in a multicentre study across the world. Total mean weight gain at 40 weeks' gestation was 13.7 (SD 4.5) $\mathrm{kg}$ for 3097 eligible women with a normal BMI in the first trimester ${ }^{3}$. Participants in our study did not report regularly for minimum 3-5 visits during the prenatal period. Hence, we could not comment on the weight gain during the pregnancy.

A study on impact of Indira Gandhi Matritva Sahyog Yojana that promotes appropriate practice, care and institutional service utilization during pregnancy, delivery and lactation; encourages the women to follow (optimal) nutrition and feeding practices, including early and exclusive breastfeeding for the first six months; provide cash incentives for improved health and nutrition to pregnant and lactating mothers; The scheme attempts to partly compensate for wage loss to pregnant and lactating women both prior to and after delivery of the child. As funds are not received on time, the implementing agencies are forced to give a lump sum amount to the beneficiaries. Most of the beneficiaries had received the funds after a year of delivery. Therefore, many of them had spent it on household expenses. Such untimely instalment of benefits has defeated the very purpose of the scheme 4 . Our study found that all the participants despite being registered for the Yojana to get monitory benefits were not equally benefited in terms of nutrition. The cash incentive is perhaps used for other household purposes. It is not effective to improve maternal nutrition and improving mother and foetus health. Hence we recommend supervised nutrition such as Mid-day meal to replace cash portion of the incentives.

Suliga found that the diet of pregnant women from the rural environment, compared to that of women from urban areas, was characterized by worse quality, resulting primarily from the lower consumption of milk and dairy products, vegetables, and juices. It was also noted that rural women more rarely took folic acid, even before becoming pregnant, and consumed meals less regularly. They recommended carrying out health education for adequate nutrition among pregnant women and, and those who plan pregnancy, directed primarily to all women from the rural environment ${ }^{5}$. Our study found that none of the women knew the importance of preconceptional folic acid supplements and diet rich in folic acid.

Hossain et al suggested that a different approach may be developed to offer rural and poor urban women the opportunity to feed themselves properly, perhaps through appropriate household or village-scale technology. They found among rural study participants that $20 \%$ were severely malnourished; $54 \%$ were malnourished; $21 \%$ were normal; and 5\% were over nourished. Further, 54\% had moderate anaemia; $24 \%$ had mild anaemia; $16 \%$ had severe anaemia; $6 \%$ were normal ${ }^{6}$. Our study found that one fourth were malnourished including $5 \%$ in the range of very severe malnutrition with BMI below 16. Majority of our participants were anaemic with only $23 \%$ having haemoglobin above $11 \mathrm{~g} / \mathrm{dL}$. One percent of the participants had severe anaemia with haemoglobin below $7 \mathrm{~g} / \mathrm{dL}$. These villages are main suppliers of milk to nearby urban areas. They are also rich in farming practices. It is unfortunate that all the produce goes for earning and the household mothers remain undernourished. It is recommended to educate the rural public to consume locally available nutritious food items.

This study revealed that $79 \%$ of the urban mothers are taking extra meals during pregnancy but only $57 \%$ in rural mothers and the difference in quantity of taking food in both the respondents were statistically significant. Most of the rural mothers in this study are lacking the awareness about the consequences of inadequate nutrition during pregnancy on mother and foetus compared to urban women. There is a significant association between women's knowledge and practices of nutrition during pregnancy ${ }^{7}$. Our study found that one fourth of the rural pregnant women were malnourished and that supports the finding that rural public is unaware about importance of nutrition in pregnancy.

Anaemia was found to be moderate public health problem in the study area. Residence, educational status, iron supplementation during pregnancy, and meal frequency per day were statistically associated with anaemia among the pregnant women. Awareness creation and nutrition education on the importance of taking iron supplementation and nutritional counselling on consumption of extra meal and iron-rich foods during pregnancy are recommended to prevent anaemia in the pregnant women ${ }^{8}$. Our study found that more than two third were anaemic that supports the finding that rural public deserved health education about importance problems of anaemia and malnutrition in pregnancy.

\section{CONCLUSION}

This study finds that rural pregnant in the study area are malnourished and anaemic. Food fads and superstitions like eggs are hot and bananas are cold; frequent fasting for religious reasons; eating leftovers after all have eaten in the home; forbidden afternoon naps and doing excessive strenuous work to facilitate normal delivery are some of the superstitions that may worsen maternal nutrition. The recommended dietary intake with frequent meals may not be actually followed. The government schemes for healthcare of pregnant women and life care of girl child are benefitting in cash to the family that may actually be used for other purposes. These schemes practically provide cash incentive for frequent and multiple pregnancy and thus potentially catapult the desired effect to worsen the situation of maternal health on one side and population control on the other. It is 
recommended that practical patterns like supervised nutritious frequent meals for pregnant women be instituted in place of cash support. The cash may be better utilized in awareness about pregnancy nutrition.

Funding: No funding sources

Conflict of interest: None declared

Ethical approval: The study was approved by the Institutional Ethics Committee

\section{REFERENCES}

1. Rao KM, Balakrishna N, Arlappa N, Laxmaiah A, Brahmam GN. Diet and nutritional status of women in India. J Hum Ecol. 2010;29(3):165-70.

2. Mavalankar DV, Trivedi CC, Gray RH. Maternal weight, height and risk of poor pregnancy outcome in Ahmedabad, India. Indian Pediatr. 1994;31(10):1205.

3. Ismail LC, Bishop DC, Pang R, Ohuma EO, Kac G, Abrams B et al. Gestational weight gain standards based on women enrolled in the Fetal Growth Longitudinal Study of the Intergrowth- $21^{\text {st }}$ Project: a prospective longitudinal cohort study. BMJ 2016;352:i555.
4. Quick evaluation study on IGMSY. Development Monitoring and Evaluation Office, NITI Aayog, Government of India, April 2017. Available at http://niti.gov.in/writereaddata/files/document_public ation/IGMSY_FinalReport.pdf accessed 21 July 2017

5. Suliga E. Nutritional behaviours of pregnant women in rural and urban environments. Ann Agric Environ Med. 2015;22(3):513-7.

6. Hossain B, Sarwar T, Reja S, Akter MN Nutritional status of pregnant women in selected rural and urban area of Bangladesh. J Nutr Food Sci. 2013;3:219.

7. Payghan BS, Kadam SS, Reddy RM. A comparative study of nutritional awareness among urban-rural pregnant mothers. RRJMHS. 2014;3(4):95-99.

8. Gebre A, Mulugeta A. Prevalence of anemia and associated factors among pregnant women in North Western Zone of Tigray, Northern Ethiopia: a crosssectional study. J Nutr Metab. 2015;2015:165430.

Cite this article as: Joshi PG, Joshi GA, Jain S, Dubey V. Nutritional status of pregnant women reporting at Rural Health Training Centre. Int J Reprod Contracept Obstet Gynecol 2017;6:3846-9. 